\title{
PENGARUH VARIASI PENAMBAHAN ABU SERBUK GERGAJI KAYU PADA PASTA SEMEN TERHADAP UJI BAHAN SEMEN
}

\author{
RASIO HEPIYANTO ${ }^{1}$, SAMSUL ARIF ${ }^{2}$ \\ Dosen Program Studi Teknik Sipil Fakultas Teknik Universitas Islam Lamongan ${ }^{1,2}$ \\ Waringinmegah_rasio@yahoo.com ${ }^{1}$, samsularif90an@gmail.com ${ }^{2}$
}

\begin{abstract}
Abstrak: Semen adalah suatu jenis bahan yang memiliki sifat adhesif dan kohesif yang memungkinkan melekatnya fragmen-fragmen mineral menjadi satu massa yang padat. Meskipun definisi ini dapat diterapkan untuk banyak jenis bahan, semen yang dimaksudkan untuk konstruksi beton adalah bahan jadi dan mengeras dengan adanya air yang dinamakan semen hidraulis. Hidraulis berarti semen bereaksi dengan air dan membentuk suatu bahan massa Komposisi kimia semen portland pada umumnya terdiri dari $\mathrm{CaO}, \mathrm{SiO} 2, \mathrm{Al} 2 \mathrm{O} 3$ dan $\mathrm{Fe} 2 \mathrm{O} 3$, yang merupakan oksida dominan. Sedangkan oksida lain yang jumlahnya hanya beberapa persen dari berat semen adalah $\mathrm{MgO}, \mathrm{SO}$, $\mathrm{Na} 2 \mathrm{O}$ dan K2O. Variasi penambahan campuran serbuk kayu berpengaruh terhadap waktu pengikatan awal sedangkan pada waktu pengikatan akhir pasta semen tidak berpengaruh (ada pengaruh tapi sangat kecil) Penambahan prosentase serbuk kayu selalu menunjukan adanya penambahan terhadap waktu pengikatan awal maupun akhir pasta semen hal ini terlihat pada hubungan waktu ikat dan prosentase semen.
\end{abstract}

Kata kunci: Beton Campuran,Serbuk kayu, Semen,Konsistensi semen, waktu ikat semen

Abstract: Cement is a type of material that has adhesive and cohesive properties that allow the attachment of mineral fragments to a solid mass. Although this definition can be applied to many types of materials, cement intended for concrete construction is finished and hardened material in the presence of water called cement hydraulis. Hidraulis means cement reacts with water and forms a mass material The chemical composition of portland cement generally consists of $\mathrm{CaO}, \mathrm{SiO} 2, \mathrm{Al} 2 \mathrm{O} 3$ and $\mathrm{Fe} 2 \mathrm{O} 3$, which are the dominant oxides. While other oxides which number only a few percent of the weight of cement are $\mathrm{MgO}, \mathrm{SO} 3, \mathrm{Na} 2 \mathrm{O}$ and $\mathrm{K} 2 \mathrm{O}$. Variations in the addition of wood powder mixture have an effect on the initial binding time, while at the end of the binding process cement paste has no effect (there is influence but very small). percentage of cement.

Keywords: Mixed Concrete, Wood Powder, Cement, Consistency of cement, cement bond time

\section{PENDAHULUAN \\ Latar Belakang}

Semen adalah suatu jenis bahan yang memiliki sifat adhesif dan kohesif yang memungkinkan melekatnya fragmenfragmen mineral menjadi satu massa yang padat. Meskipun definisi ini dapat diterapkan untuk banyak jenis bahan, semen yang dimaksudkan untuk konstruksi beton adalah bahan jadi dan mengeras dengan adanya air yang dinamakan semen hidraulis. Hidraulis berarti semen bereaksi dengan air dan membentuk suatu bahan massa.

Komposisi kimia semen portland pada umumnya terdiri dari $\mathrm{CaO}$, $\mathrm{SiO} 2, \mathrm{~A} 12 \mathrm{O} 3$ dan $\mathrm{Fe} 2 \mathrm{O} 3$, yang merupakan oksida dominan. Sedangkan oksida lain yang jumlahnya hanya beberapa persen dari berat semen adalah $\mathrm{MgO}, \mathrm{SO}$, $\mathrm{Na} 2 \mathrm{O}$ dan $\mathrm{K} 2 \mathrm{O}$.
Keempat oksida utama tersebut diatas di dalam semen berupa senyawa $\mathrm{C} 3 \mathrm{~S}, \mathrm{C} 2 \mathrm{~S}, \mathrm{C} 3 \mathrm{~A}$ dan $\mathrm{C} 4 \mathrm{AF}$, dengan mempunyai perbandingan tertentu pada setiap produk semen, tergantung pada komposisi bahan bakunya

Adapun tujuan dari penelitian ini adalah:

1. Untuk mengetahui dan membandingkan antara pengaruh subtitusi semen dengan beberapa variasi campuran terhadap waktu ikat semen.

2. Untuk mengetahui sifat dari semen pada campuran pasta semen sebagai retarder atau accelerator.

\section{METODE PENELITIAN}

Penelitian ini merupakan penelitian eksperimen. Penelitian ini dilakukan dengan cara pengujian dilabolatrium sesuai dengan data-data dari studi pustaka menggunakan 
standart SNI beton. Sampel yang dibuat adalah beton segar dengan perbandingan komposisi campuran yang menggunakanabu serbuk kayu sebagai bahan campuran beton.

\section{Bagan Alur Penelitian}

Pembuatan benda uji campuran pasta semen menggunakan metode Standar Nasional Indonesia yaitu SNI 036826-2002 untuk pengujian konsistesi semen dan SNI 03-68272002 untuk Pengujian waktu ikat semen.

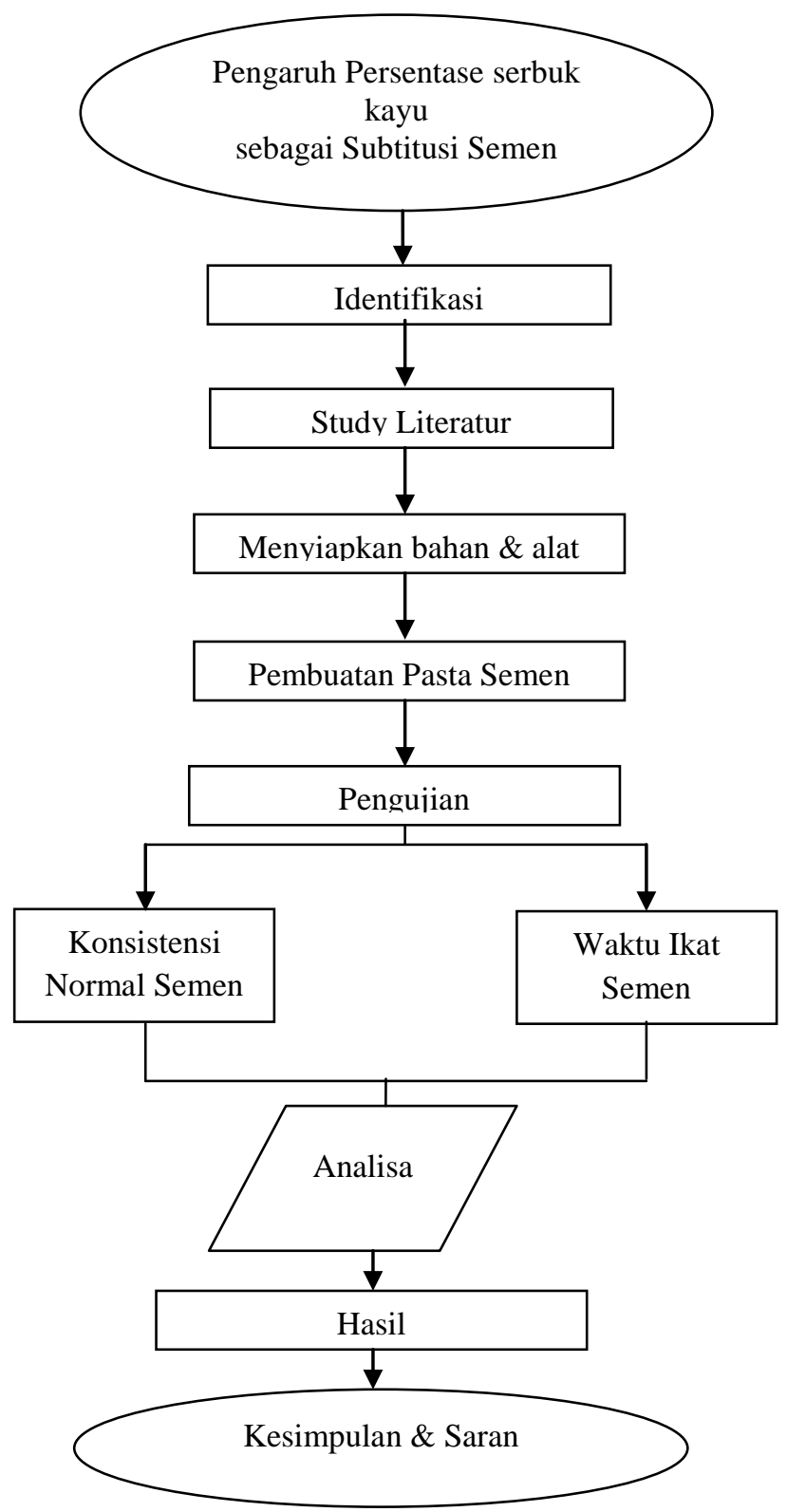

Jenis Penelitian

a. Pengujian kuat tekan berdasarkan SNI 031974-1990.

b. Metode penelitian yang digunakan adalah job mix design dengan menggunakan standart SNI 03-2834-2000 dengan mutu beton.

Dalam melakukan metode pengujian acuan yang dipakai adalah SNI, Diktat Praktikum Bahan Beton Universitas Islam Lamongan (UNISLA).

\section{Analisis Semen}

Metode terhadap semen meliputi: Analisis konsistensi semen, percobaan waktu pengikatan dan pengerasan semen, percobaan berat jenis semen

1. Analisis konsistensi semen

2. Pengujian waktu pengikat dan pengerasan semen

3. Pengujian berat jenis semen

\section{Analisis Agregat}

Metode terhadap agregat halus meliputi : analisa saringan, Analisa berat jenis, Analisa kadar air resapan dan analisa berat volume.
1. Analisa Saringan
2. Analisis Berat Jenis
3. Analisa Air Resapan Pasir

\section{Prosedur Pelaksanaan Beton (ASTM C 192 $-90 \mathrm{~A})$}

Setelah mendapatkan hasil perhitungan dari perencanaan mix design, langkah selanjutnya adalah membuat campuran beton. Metode pelaksanaannya di mulai dengan menimbang bahan sesuai dengan sesuai dengan kebutuhan mix design lalu di aduk dalam molen sampai semua material tercampur rata.

Setelah semua bahan tercampur rata, ambil sebagian campuran beton atau pasta beton dengan sendok spesi untuk dilakukan tes berat volume beton segar dengan uji slump. Apabila slump yang di dapat tidak sesuai dengan yang di kehendaki, ulangi pengerjaan dengan menambah atau mengurangi bahan material sampai mendapat slump yang di kehendaki.

Masukkan pasta beton ke dalam silinder $\Theta 15 \mathrm{~cm}$ dan tinggi $30 \mathrm{~cm}$, sambil di padatkan dengan alat perojoksetiap $1 / 3$ bagiannya sampai penuh. Diamkan selama 24 jam, setelah 24 jam keluarkan benda uji dari dalam cetakan, lalu merendam benda uji dalam wadah berisi air selama 7 hari.

$\begin{array}{lrr}\text { Fakultas Teknik UMSB } & \text { ISSN 2599-2081 } \\ \text { EISSN 2599-2090 }\end{array}$




\section{Prosedur Perawatan Beton}

Perawatan beton dilakukan setelah beton mencapai final setting, artinya beton telah mengeras. Perawatan ini dilakukan agar proses hidrasi selanjutnya tidak mengalami gangguan. Jika hal ini terjadi, Beton akan terjadi keretakan karena kehilangan air yang begitu cepat.Perawatan ini dilakukan minimal selama 7 hari dan beton berkekuatan awal tinggi minimal 3 hari serta harus dipertahankan dalam kondisi lembap, kecuali dilakukan perawatan yang lebih cepat (PB. 1989:29)

Perawatan ini tidak dimaksud untuk mendapat kekuatan tekan beton yang tinggi, tapi juga dimaksud untuk memperbaiki mutu dari keawetan, kekedapan terhadap air , ketahanan terhadap aus, serta stabilitas dari dimensi struktur.

\section{HASIL DAN PEMBAHASAN \\ Hasil Uji Material penggunaan semen.}

Data - data pengujian yang di olah meliputi referensi sebagai berikut :

\section{Semen}

Semen yang digunakan merupakan semen Portland.Pengujian terhadap semen berupa uji fisik bertujuan untuk mengetahui kondisi kebasahan pasta yang standart yang dilakukan di laboratorium Teknik Sipil Universitas Islam Lamongan (Unisla). Dengan pengujian yang tertera sebagai berikut :

a. Percobaan konsitensi semen

b. Percobaan waktu pengikat dan mengeras semen

c. Percobaan berat jenis semen

\section{Pengujian konsistensi normal semen}

Dari hasil pengujian konsistensi normal semen Portland(ASTM C 187-86)adalah sebagai berikut :

Tabel 1 Pengujian konsistensi normal semen

\begin{tabular}{|c|c|c|c|}
\hline $\begin{array}{c}\text { Percobaan } \\
\text { Nomor }\end{array}$ & $\mathbf{1}$ & $\mathbf{2}$ & $\mathbf{3}$ \\
\hline Berat Semen & 250 & 250 & 250 \\
\hline Berat Air & 70 & 80 & 90 \\
\hline $\begin{array}{c}\text { Penurunan } \\
\text { (mm) }\end{array}$ & 10 & 15 & 19 \\
\hline Konsistensi & $28 \%$ & $32 \%$ & $36 \%$ \\
\hline
\end{tabular}

Sumber : Hasil Penelitian

Dari tabel 1 di peroleh konsistensi semen portland normal sebesar $28 \%$ untuk berat air
$70 \mathrm{cc}$ dan penurunan sebanyak $10 \mathrm{~mm}, 32 \%$ untuk berat air $80 \mathrm{cc}$ dan menghasilkan penurunan sebanyak $15 \mathrm{~mm}, 36 \%$ untuk berat air $90 \mathrm{cc}$ dan menghasilkan penurunan sebanyak $19 \mathrm{~mm}$.

\section{Pengujian Waktu Pengikatan Dan Pengerasan Semen}

Dari hasil waktu pengikatan dan pengerasan semen(ASTM 119-92) adalah sebagai berikut :

Tabel 2 Pengujian waktu dan pengerasan semen

\begin{tabular}{|c|c|c|}
\hline NO & $\begin{array}{c}\text { WAKTU } \\
\text { PENURUNAN } \\
\text { (MENIT) }\end{array}$ & $\begin{array}{c}\text { PENURUNAN(M } \\
\text { M) }\end{array}$ \\
\hline 1 & 45 & 6 \\
\hline 2 & 60 & 6 \\
\hline 3 & 75 & 6 \\
\hline 4 & 90 & 5 \\
\hline 5 & 105 & 3 \\
\hline 6 & 120 & 1 \\
\hline
\end{tabular}

Sumber : Hasil penelitian

Dari tabel 2 di peroleh waktu pengikat dan pengerasan semen Portlan selama \pm 2 jam untuk memperoleh syarat standart yakni pengikat akhir sampai $0 \mathrm{~mm}$.

Pengujian berat jenis semen

Dari hasil penelitian, diketahui nilai normal berat jenis semen (ASTM C 188 - 89) sebagai berikut :

Tabel 3 Pengujian berat jenis semen normal

\begin{tabular}{|l|c|c|}
\hline PERCOBAAN NOMOR & I & II \\
\hline Berat Semen (w1) - (gr) & 250 & 250 \\
\hline $\begin{array}{l}\text { Berat semen+minyak+labu } \\
\text { takar (w2) - (gr) }\end{array}$ & 494 & 491.2 \\
\hline $\begin{array}{l}\text { Berat labu takar+minyak } \\
\text { (w3) - (gr) }\end{array}$ & 328.5 & 328.5 \\
\hline $\begin{array}{l}\text { Bj = 0.8 w1 / (w1 + w3 - } \\
\text { w2) }\end{array}$ & 2.366 & 2.290 \\
\hline
\end{tabular}

Sumber : Hasil penelitian

Dari tabel 3 diperoleh hasil pengujian pertama berat semen memperoleh nilai 2.366 gr, sedangkan untuk hasil pengujian kedua memperoleh nilai sebesar 2.290 gr.

Dari percobaan pengujian berat jenis semen di peroleh nilai rata - rata 2.328 gr. Menurut ketentuan SNI 15-2531-1991 berat jenis semen yakni antara $3,00-3,20 \mathrm{t} / \mathrm{m}^{3}$, jadi berat jenis 
semen tersebut tidak memenuhi standart ketentuan yang di tetapkan.

\section{Pengujian Semen Dengan Campuran Abu Serbuk Gergaji Kayu 5\%}

Dari hasil penelitian, di ketahui nilai konsistensi semen portland dan abu serbuk gergaji kayu 5\% sebagai berikut :

Tabel 4 Pengujian konsistensi semen dengan

$$
\text { campuran } 5 \%
$$

\begin{tabular}{|c|c|c|c|}
\hline $\begin{array}{l}\text { Percobaan } \\
\text { Nomor }\end{array}$ & $\mathbf{1}$ & $\mathbf{2}$ & $\mathbf{3}$ \\
\hline Berat Semen & 237 & 237 & 237 \\
\hline $\begin{array}{c}\text { berat abu } \\
\text { serbuk kayu }\end{array}$ & 12,5 & 12,5 & 12,5 \\
\hline Berat Air & 65 & 70 & 75 \\
\hline $\begin{array}{c}\text { Penurunan } \\
\text { (mm) }\end{array}$ & 6 & 10 & 15 \\
\hline Konsistensi & $26 \%$ & $28 \%$ & $30 \%$ \\
\hline
\end{tabular}

Sumber : Hasil Penelitian

Dari tabel 4 diperoleh nilai konsistensi semen portland dengan campuran abu serbuk kayu $5 \%$ sebesar $26 \%$ untuk berat air $65 \mathrm{cc}$ dan penurunan sebanyak $6 \mathrm{~mm}, 28 \%$ untuk berat air $70 \mathrm{cc}$ dan menghasilkan penurunan sebanyak $10 \mathrm{~mm}, 30 \%$ untuk berat air $75 \mathrm{cc}$ dan menghasilkan penurunan sebanyak 15 $\mathrm{mm}$.

\section{Waktu Pengikatan Dan Pengerasan Semen Dengan Campuran Abu Serbuk Gergaji Kayu 5\%}

Dari hasil penelitian, diketahui nilai waktu pengikatan dan pengerasan semen (ASTM 119-92)campuran abu serbuk gergaji kayu 5\% sebagai berikut :

Tabel 5 Pengujian waktu ikat dan pengerasan semen dengan campuran 5\%

\begin{tabular}{|c|c|c|}
\hline NO & $\begin{array}{c}\text { WAKTU } \\
\text { PENURUNAN } \\
\text { (MENIT) }\end{array}$ & $\begin{array}{c}\text { PENURUNAN } \\
\text { (MM) }\end{array}$ \\
\hline 1 & 45 & 5 \\
\hline 2 & 60 & 4 \\
\hline 3 & 75 & 3 \\
\hline 4 & 90 & 2 \\
\hline 5 & 105 & 0 \\
\hline
\end{tabular}

Sumber :Hasil penelitian

Dari tabel 5 di peroleh waktu pengikat dan pengerasan semen Portland selama \pm 2 jam untuk memperoleh syarat standart yakni pengikat akhir sampai $0 \mathrm{~mm}$.
Berat Jenis Semen Dengan campuran abu serbuk gergaji kayu 5\%

Dari hasil penelitian, di ketahui nilai berat jenis semen dengan campuran abu serbuk gergaji kayu 5\% adalah sebagai berikut :

Tabel 6 Pengujian Berat Jenis semen dengan campuran $5 \%$

\begin{tabular}{|c|c|c|}
\hline PERCOBAAN NOMOR & I & II \\
\hline Berat Semen (w1)-(gr) & 237 & 237 \\
\hline $\begin{array}{c}\text { berat abu serbuk kayu } \\
\text { (w2)-(gr) }\end{array}$ & 12,5 & 12,5 \\
\hline $\begin{array}{c}\text { Berat semen + 5\% } \\
\text { campuran +minyak+labu } \\
\text { takar (w3) - (gr) }\end{array}$ & 745 & 750 \\
\hline $\begin{array}{c}\text { Berat labu takar+minyak } \\
(w 4)-(g r)\end{array}$ & 554 & 554 \\
\hline $\begin{array}{c}\text { Bj = 0.8 (w1 +w2)/ } \\
((w 1+w 2)+w 4-w 3)\end{array}$ & 3,390 & 3,704 \\
\hline
\end{tabular}

Sumber : Hasil Penelitian

Dari tabel 6 diperoleh hasil pengujian pertama berat semen memperoleh nilai 3,390gr, sedangkan untuk hasil pengujian kedua memperoleh nilai sebesar 3,704 gr.

Dari percobaan pengujian berat jenis semen di peroleh nilai rata - rata 3,546 gr. Menurut ketentuan SNI 15-2531-1991 berat jenis semen yakni antara $3,00-3,20 \mathrm{t} / \mathrm{m}^{3}$, jadi berat jenis semen tersebut tidak memenuhi standart ketentuan yang di tetapkan.

\section{Pengujian Semen Dengan Campuran Abu serbuk gergaji kayu $7 \%$}

Hasil dari penelitian, di ketahui nilai konsistensi semen porland dan abu serbuk gergaji kayu 7\% sebagai berikut :

Tabel 7 Pengujian Konsistensi semen dengan campuran $7 \%$

\begin{tabular}{|l|c|c|c|}
\hline Percobaan Nomor & $\mathbf{1}$ & $\mathbf{2}$ & $\mathbf{3}$ \\
\hline Berat Semen & 232 & 232 & 232 \\
\hline $\begin{array}{l}\text { berat abu serbuk } \\
\text { kayu }\end{array}$ & 17,5 & 17,5 & 17,5 \\
\hline Berat Air & 70 & 75 & 85 \\
\hline Penurunan $(\mathrm{mm})$ & 4 & 5 & 10 \\
\hline Konsistensi & $28 \%$ & $30 \%$ & $34 \%$ \\
\hline
\end{tabular}

Sumber : Hasil Penelitian

Dari tabel 7 diperoleh nilai konsistensi semen portland dengan campuran abu serbuk kayu $7 \%$ sebesar $28 \%$ untuk berat air $70 \mathrm{cc}$ dan penurunan sebanyak $4 \mathrm{~mm}, 30 \%$ untuk berat air $75 \mathrm{cc}$ dan menghasilkan penurunan sebanyak $5 \mathrm{~mm}, 34 \%$ untuk berat air $85 \mathrm{cc}$ dan menghasilkan penurunan sebanyak $10 \mathrm{~mm}$. 


\section{Waktu Ikat Semen Dan Abu Serbuk \\ Gergaji Kayu 7 \%}

Dari hasil penelitian, diketahui waktu pengikatan dan pengerasan semen (ASTM 119-92)campuran abu serbuk gergaji kayu 7\% sebagai berikut :

Tabel 8 Pengujian waktu pengikat dan pengerasan semen dengan campuran $7 \%$

\begin{tabular}{|c|c|c|}
\hline NO & $\begin{array}{c}\text { WAKTU } \\
\text { PENURUNAN } \\
\text { (MENIT) }\end{array}$ & $\begin{array}{c}\text { PENURUN } \\
\text { AN(MM) }\end{array}$ \\
\hline 1 & 45 & 23 \\
\hline 2 & 60 & 9 \\
\hline 3 & 75 & 4 \\
\hline 4 & 90 & 3 \\
\hline 5 & 105 & 0 \\
\hline
\end{tabular}

Sumber : Hasil penelitian

Dari tabel 8 di peroleh waktu pengikat dan pengerasan semen Portland selama 105 menit untuk memperoleh syarat standart yakni pengikat akhir sampai $0 \mathrm{~mm}$.

\section{Uji Berat Jenis Semen Dan Abu serbuk gergaji kayu}

Dari hasil penelitian, diketahui nilai berat jenis semen dengan campuran abu serbuk gergaji kayu 7\% sebagai berikut :

Tabel 9 Pengujian berat jenis semen dengan campuran $7 \%$

\begin{tabular}{|l|c|c|}
\hline PERCOBAAN NOMOR & I & II \\
\hline Berat Semen (w1)-(gr) & 232,5 & 232,5 \\
\hline $\begin{array}{l}\text { berat abu serbuk kayu } \\
\text { (w2)-(gr) }\end{array}$ & 17,5 & 17,5 \\
\hline $\begin{array}{l}\text { Berat semen+7\% } \\
\text { campuran +minyak+labu } \\
\text { takar (w3)-(gr) }\end{array}$ & 738 & 742 \\
\hline $\begin{array}{l}\text { Berat labu takar+minyak } \\
(\mathrm{w} 4)-(\mathrm{gr})\end{array}$ & 554 & 554 \\
\hline $\begin{array}{l}\text { Bj = 0.8 (w1 +w2)/ } \\
((\mathrm{w} 1+\mathrm{w} 2)+\mathrm{w} 4-\mathrm{w} 3)\end{array}$ & 3,030 & 3,226 \\
\hline
\end{tabular}

Sumber : Hasil penelitian

Dari tabel 9 diperoleh hasil pengujian pertama berat semen memperoleh nilai 3,030gr, sedangkan untuk hasil pengujian kedua memperoleh nilai sebesar 3,226 gr. Perbedaan dari penelitian ini terletak pada nilai perolehan timbangan berat semen + abu serbuk kayu dan labu takar.

Dari percobaan pengujian berat jenis semen di peroleh nilai rata - rata 3,128 gr. Menurut ketentuan SNI 15-2531-1991 berat jenis semen yakni antara $3,00-3,20 \mathrm{t} / \mathrm{m}^{3}$, jadi berat jenis semen tersebut memenuhi standart ketentuan yang di tetapkan.

\section{Pengujian Semen Dengan Campuran Abu Serbuk Kayu $10 \%$}

Dari hasil penelitian, diketahui nilai konsistensi semen dan abu serbuk gergaji kayu 10\% sebagai berikut :

Tabel 10 Pengujian Konsistensi semen dengan campuran $10 \%$

\begin{tabular}{|l|c|c|c|}
\hline Percobaan Nomor & $\mathbf{1}$ & $\mathbf{2}$ & $\mathbf{3}$ \\
\hline Berat Semen & 225 & 225 & 225 \\
\hline Berat Abu serbuk kayu & 25 & 25 & 25 \\
\hline Berat Air & 85 & 88 & 90 \\
\hline Penurunan (Mm) & 4 & 10 & 15 \\
\hline Konsistensi & $34 \%$ & $35 \%$ & $36 \%$ \\
\hline
\end{tabular}

Sumber : Hasil penelitian

Dari tabel 10 diperoleh nilai konsistensi semen portland dengan campuran abu serbuk kayu $10 \%$ sebesar $34 \%$ untuk berat air $85 \mathrm{cc}$ dan penurunan sebanyak $4 \mathrm{~mm}, 35 \%$ untuk berat air $88 \mathrm{cc}$ dan menghasilkan penurunan sebanyak $10 \mathrm{~mm}, 36 \%$ untuk berat air $90 \mathrm{cc}$ dan menghasilkan penurunan sebanyak 15 $\mathrm{mm}$.

\section{Pengujian Waktu Ikat Semen Dengan Campuran Abu Serbuk Kayu 10 \%}

Dari hasil penelitian, diketahui waktu pengikatan dan pengerasan semen(ASTM 11992) campuran abu serbuk kayu10\% sebagai berikut :

Tabel 11 Pengujian waktu ikat dan pengerasan semen dengan campuran $10 \%$

\begin{tabular}{|c|c|c|}
\hline NO & $\begin{array}{c}\text { WAKTU } \\
\text { PENURUNAN } \\
\text { (MENIT) }\end{array}$ & $\begin{array}{c}\text { PENURUNAN( } \\
\text { MM) }\end{array}$ \\
\hline 1 & 45 & 22 \\
\hline 2 & 60 & 14 \\
\hline 3 & 75 & 7 \\
\hline 4 & 90 & 5 \\
\hline 5 & 105 & 4 \\
\hline 7 & 120 & 2 \\
\hline 8 & 135 & 0 \\
\hline
\end{tabular}


Sumber : Hasil penelitian

Dari tabel 11 di peroleh waktu pengikat dan pengerasan semen Portland selama 135 menit untuk memperoleh syarat standart yakni pengikat akhir sampai $0 \mathrm{~mm}$.

\section{Pengujian Berat Jenis Semen Dan Abu Serbuk Kayu $10 \%$}

Dari hasil penelitian, diketahui nilai berat jenis semen dan abu serbuk kayu $10 \%$ sebagai berikut :

Tabel 12 Pengujian berat jenis semen dengan campuran $10 \%$

\begin{tabular}{|l|c|c|}
\hline PERCOBAAN NOMOR & I & II \\
\hline Berat Semen (w1)-(gr) & 225 & 225 \\
\hline $\begin{array}{l}\text { berat abu serbuk kayu } \\
\text { (w2)-(gr) }\end{array}$ & 25 & 25 \\
\hline $\begin{array}{l}\text { Berat semen+minyak+labu } \\
\text { takar (w3)-(gr) }\end{array}$ & 741 & 746 \\
\hline $\begin{array}{l}\text { Berat labu takar+minyak } \\
(\mathrm{w} 4)-(\mathrm{gr})\end{array}$ & 554 & 554 \\
\hline $\begin{array}{l}\text { Bj = 0.8 (w1 +w2)/ } \\
((\mathrm{w} 1+\mathrm{w} 2)+\mathrm{w} 4-\mathrm{w} 3)\end{array}$ & 3,175 & 3,448 \\
\hline
\end{tabular}

Sumber : Hasil penelitian

Dari tabel 12 diperoleh hasil pengujian pertama berat semen memperoleh nilai $3,175 \mathrm{gr}$, sedangkan untuk hasil pengujian kedua memperoleh nilai sebesar 3,448 gr. Perbedaan dari penelitian ini terletak pada nilai perolehan timbangan berat semen + abu serbuk kayu dan labu takar.

Dari percobaan pengujian berat jenis semen di peroleh nilai rata - rata 3,311 gr. Menurut ketentuan SNI 15-2531-1991 berat jenis semen yakni antara $3,00-3,20 \mathrm{t} / \mathrm{m}^{3}$, jadi berat jenis semen tersebut tidak memenuhi standart ketentuan yang di tetapkan.

\section{SIMPULAN DAN SARAN Simpulan}

Dari hasil penelitian dan pembahasan di simpulkan bahwa uji bahan semen dan campuran adalah

1. Variasi penambahan campuran serbuk kayu berpengaruh terhadap waktu pengikatan awal sedangkan pada waktu pengikatan akhir pasta semen tidak berpengaruh (ada pengaruh tapi sangat kecil)

2. Penambahan prosentase serbuk kayu selalu menunjukan adanya penambahan terhadap waktu pengikatan awal maupun akhir pasta semen hal ini terlihat pada hubungan waktu ikat dan prosentase semen.

\section{Saran}

Adapun saran yang dapat diberikan dari penelitian ini adalah sebagai berikut:

1. Perlu dilakukan penelitian lebih lanjut dengan variasi yang berbeda.

2. Hasil penelitian menunjukkan bahwa penggunaan serbuk kayu dalam jumlah besar sebagai bahan stabilisasi tidak begitu dianjurkan.

\section{UCAPAN TERIMA KASIH}

Dalam penyusunan penelitian ini tidak terlepas dari dukungan berbagai pihak. Penulis seara khusus mengucapkan terima kasih kepada DPRM Dikti yang telah memberikan hibah penelitian dosen pemula (PDP) sehingga penyusunan penelitian ini dapat berjalan lancar

\section{DAFTAR PUSTAKA}

Melvin Junius Indra

dkk.2013.PEMANFAATAN ABU

LIMBAH GERGAJI KAYU SEBAGAI

CAMPURAN PEMBUATAN BETON

(Jurnal).Jurusan Teknik Sipil :

Universitas kristen petra

Fauzi Fakhri dan

Nursyamsi.2007.PEMANFAATAN

LIMBAH SERBUK KAYU SEBAGAI

SUBTITUSI AGREGAT HALUS PADA

BETON (Jurnal). Sumatera Utara.

Jurusan Teknik Sipil :Universitas

Sumatera Utara, Medan

Maricar Syama.2014.PEMANFAATAN

CAMPURAN MORTAR DAN

PARTIKEL KAYU SEBAGAI ELEMEN

INTI BALOK BETON KOMPOSIT

(Jurnal).Palu : Universitas Tadaluko

Edison Bambang.2011.PENGGUNAAN IJUK

DAN SABUT KELAPA TERHADAP

KUAT TEKAN PADA BETON K-200

(Jurnal).Jurusan

Teknik

Sipil.Universitas Pasir Pengaraian.

Kusumangtyas Putri.2014.KAJIAN RINGAN DENGAN MENGGUNAKAN SERBUK KAYU SEBAGAI PENGGANTI AGREGAT HALUS (Artikel).Jurusan Teknik Sipil.Universitas Politeknik Negeri Sriwijaya 